\title{
MODERN WAYS OF WORKING: COMPARING RESULTS OF TWO PILOT STUDIES
}

\author{
Ieva KALVE ${ }^{1}$, Sebastian CAPOTESCU ${ }^{2}$ \\ ${ }^{1}$ Riga Stradiňš University, Riga, Latvia \\ ${ }^{2}$ GreenForest S.R.L., Timisoara, Romania \\ Corresponding authore-mail: ieva.kalve@rsu.lv
}

\begin{abstract}
This article provides a concise look into the theoretical basis and two small pilot studies which serve as the beginning of a further research collaboration, and have been done in 2018-2019 in service industry companies in Riga (Latvia) and Timisoara (Romania). The objective of these studies was to find the respondents' knowledge about new ways of working (full or partial remote work, co-working spaces, etc.), as well as their personal fit with these types of work, among other questions. Results of these studies show that there is a significant difference between the theory, the respondent answers, and the actions of their organizations. Main recommendations: there is no single correct approach, it has to be aligned with the business strategy and the actual work specifics of various departments or positions in the company. Problems faced by the workforce must also be taken into account, instead of aiming to decrease office costs as much as possible by creating hot-desking or other similar open office layouts.
\end{abstract}

Keywords: Office design, Remote work, Service management, Strategic management, Workplace.

JEL Classification: M51

\section{INTRODUCTION}

For centuries, it has been well known that business cannot exist without the three „W"s: work, workforce and workplace. Even though this principle is still valid, various authors (Blok, van der Meulen, \& Dhondt, 2016; Capotescu, Malaies, \& Soim, 2019; Kalve, 2019; McAtamney, Aickin, Caple, Caponecchia, \& Mackey, 2017; Schwab, 2019) note that the perception and understanding of what is an optimal working space is changing, especially for office work which is constantly increasing in scope, including a wide range of IT specialists and other service providers. Some time ago, employees (including those in offices) thought that workplace is something given/fixed, which is a sole responsibility of the employer with no input from the employee, but this thinking has significantly changed in the past few decades. The fact that technology makes it possible to work remotely, as well as increasingly popular project based work and work in teams, in addition to the ever growing deficit of competent employees have made us review the role and importance of a working space, which can be seen by the growing number of studies on the topic (Choudhury, Larson, \& Foroughi, 2019; McAtamney et al., 2017; Oldman, 2018).

Some time ago, it was enough that the employer tried to use their knowledge of the business logic and needs, and tried to decrease costs as much as possible, to set up the working spaces. Currently, however, not all employers are aware of and understand the possibilities provided by modern technology, or just refuse to implement them for various 
reasons, while the employees are well-informed and increasingly want full or partial remote work, or work from co-working spaces (Choudhury et al., 2019; Kelliher \& Anderson, 2010; Stegmeier, 2008).

A typical example - to save costs, employers often choose to implement an open-office working space, despite the fact that employees are mostly negative towards these spaces, often noting that they are unsuitable for both themselves and the type of work they are doing (James, 2018; Wohlers \& Hertel, 2017). Researchers are against such simplistic approach by the employers, and note that different organizations and types of work would require different working spaces, and some even talk about employee-centric workplaces (Brunia, De Been, \& van der Voordt, 2016; Manca, Grijalvo, Palacios, \& Kaulio, 2018; Oldman, 2018).

This article is a third part of larger research which was done as part of the "Generations@Work" project. Generations@Work research is motivated by challenges of the "Future of Work" thinking domain, social integration and the business challenges of recruitment and integration of the native digital generation with the today workplaces. The first two articles, consisting mostly of the theoretical overview of the research topic, were created for the 15th International Symposium in Management (SIM): Innovation for Sustainable Management and Entrepreneurship, which took place in October 2019, in Timisoara, Romania. The articles were published in the SIM conference article collection.

The objective of this publication is to compare and analyze the results of two small pilot studies, made in Latvia and Romania, about employee knowledge of the new ways of working.

\section{METHODOLOGY}

Surveys to determine employee knowledge about the new ways of working, and how they value them, were done in the 2018 - 2019 in Latvia and Romania, using a multiple choice Google Forms online tool. In Latvia, the survey was done in English in a shared service center, and 54 valid responses were received. In Romania, the survey was public, in Romanian language, with respondents mostly from Timisoara and its nearby regions; 94 valid responses were received. Information about the respondents is shown in Table 1:

Table 1. Information about the respondents (in percent of the total)

\begin{tabular}{|l|c|c|c|c|c|c|c|c|c|c|}
\hline \multirow{2}{*}{$\%$} & \multicolumn{4}{|c|}{ Age group } & \multicolumn{6}{c|}{ Type of professional activity } \\
\cline { 2 - 12 } & $\begin{array}{c}\text { under } \\
25\end{array}$ & $25-35$ & $36-50$ & $\begin{array}{c}\text { above } \\
50\end{array}$ & $\begin{array}{c}\text { opera- } \\
\text { tional }\end{array}$ & $\begin{array}{c}\text { decision- } \\
\text { making }\end{array}$ & $\begin{array}{c}\text { team } \\
\text { mana- } \\
\text { gement }\end{array}$ & $\begin{array}{c}\text { self- } \\
\text { employed }\end{array}$ & $\begin{array}{c}\text { multiple } \\
\text { roles }\end{array}$ & $\begin{array}{c}\text { not } \\
\text { answe- } \\
\text { red }\end{array}$ \\
\hline $\begin{array}{l}\text { Romania, } \\
\# 94\end{array}$ & 12 & 41 & 37 & 10 & 32 & 10 & 2 & 41 & 14 & 1 \\
\hline $\begin{array}{l}\text { Latvia, } \\
\# 54\end{array}$ & 20 & 67 & 13 & 0 & 63 & 30 & 7 & 0 & 0 & 0 \\
\hline
\end{tabular}

Data in Table 1 shows that respondents in Latvia were younger (87\% aged 35 or younger, while only $53 \%$ of Romania's respondents are in that age interval), and with a lower (operational) position in the company (63\% in Latvia, and 32\% in Romania), which has been taken into account when analyzing the survey results.

Limitations of the survey. The survey found the respondents' opinion on four types of modern ways of working: Home office partial (HOP), Home office total (HOT), Flex office (Flex), and Co-working spaces (CoW). By Home office we refer to full-time or part-time 
work in home. Flex office refers to non-personal and non-tertiary workspaces, also called hot desk or shared desk, which are generally linked to spaces that create better facilities for meetings, concentration, creative activities, learning activities, and more. Through Coworking, we refer to activities in leased areas, usually on an individual and short-term basis, or only for certain activities, often by people with diverse, often complementary activities that might also be carried out at home, done in an environment with more social relationships that interfere frequently and professionally.

Since each question had multiple possible answers and the respondents were permitted to choose more than one answer, only the most contrasting and/or dominating answers will be highlighted in this article. This article has fewer notes on Flex and CoW, as they combined for a small share of the answers in most questions, showing that the respondents to this survey were more interested in HOP and HOT. In a few questions, both of options for working from home were joined together as Home Office (HO). There were no questions on Open-office working spaces, as that is not a new way of working.

Due to the slightly differing interests of the researchers, not all questions were the same in both countries. Only the four questions that were identical will be used for analysis as part of this article:

1) Do you know/had read or heard about the new ways of working?

2) Do you have experience with the new ways of working?

3) How do you evaluate the new ways of working for you personally?

4) In your opinion, what are the benefits of new ways of working?

\section{RESULTS AND INTERPRETATION}

First, the respondents' knowledge of new ways of working was determined. $61 \%$ of Romanian respondents noted that they know something about all four options, which was also the case for $28 \%$ of Latvian respondents. $63 \%$ of Latvian and $76 \%$ of Romanian respondents knew something about at least three of the new ways of working. These quite significant differences can be explained with the fact that Latvian respondents were younger, and for some this was their first full-time job, so they had not an opportunity to compare and learn about these new ways of working. Overall, it was clear that the level of understanding is high, with only $4 \%$ of respondents saying that they do not know anything about these new ways of working.

When asked about practical experience, it showed that only $28 \%$ of Romanian respondents have an opportunity to work HOP, while in Latvia that grew to $50 \%$. Since all Latvian respondents were from the same company, this shows that this employer gives HOP option to at least part of its employees. At the same time, only $6 \%$ of Latvian respondents said that they work HOT, with the number increasing to $11 \%$ in Romania. This demonstrates that while the Latvian company encourages HOP work for its employees, HOT is not as available. The reason behind that could be the type of work this company does, as its employees are mostly doing administrative/operational work. HOT proportion that is nearly two times higher in Romania could be explained by the fact that $41 \%$ of the respondents were self-employed, with that work generally taking place outside of the classic working spaces. Interestingly, $18 \%$ of Romanian and $6 \%$ of Latvian respondents noted that they are currently using more than one new way of working. In Romania, that could be because of the high proportion of self-employed respondents $(41 \%)$, who could possibly be switching 
between $\mathrm{HO}$, office and $\mathrm{CoW}$, and also work in or for multiple organizations. The $6 \%$ of Latvian respondents using multiple new ways of working could be explained by the fact that some HOP workers use co-working spaces.

A similar proportion of respondents in both countries do not use, or do not have an opportunity to use, the new ways of working: $20 \%$ in Romania and $22 \%$ in Latvia. The positive note here is that this is a small number - only one fifth of the respondents are not using the new ways of working, despite the fact that a bit more than 10 years ago almost everyone was working from the working space provided by the employer.

An even more interesting comparison is between the ways of working of family members. $38 \%$ in Romania and $56 \%$ in Latvia note that none of their family members use new ways of working, meaning that the respondents themselves are more of an exception. Only $19 \%$ in Romania and $7 \%$ in Latvia note that some of their family members work HOP, with $11 \%$ and $7 \%$, respectively, having family members working in HOT, but the new ways of working are combined for family members of $7 \%$ in Romania and $11 \%$ in Latvia. These numbers lag significantly behind the level of respondents themselves, and mean that the particular Latvian employer is very progressive, while the Romanian respondents seem to be people who are involved and/or interested in the new ways of working more than the average person.

These varying answers create a question of whether all service management field employees could and should have access to the new ways of working. The opinion of respondents was gathered in two questions. First: which, if any, new ways of working would be suitable for the respondents themselves, with the respondents choosing "fit", "possible", or "inappropriate" for each of the four ways of working. 64\% of Romanian and $72 \%$ of Latvian respondents chose that HOP would "fit" themselves, with $32 \%$ and $28 \%$, respectively, choosing that it would be "possible", and 4\% in Romania noting that it would be "inappropriate". This positive attitude towards HOP is in line with the results of other studies, which note that productivity and employee happiness increases when working from home, while the number of days on sick leave decreases (James, 2019). At the same time, it is important to note that HOP could be the most expensive option for the employer - how can they provide an optimal number of working spaces if they are not used permanently? The classic open-office would be ineffective in this case. Here, a flex-office approach with various types of working spaces or zones, which employees choose based on the task at hand, would be more appropriate (Kelliher \& Anderson, 2010; Manca et al., 2018).

When it comes to their fit for HOT work, the respondents' answers are significantly different: $45 \%$ in Romania and $31 \%$ in Latvia deem it to be "inappropriate". Only $18 \%$ in Romania and $26 \%$ in Latvia put it down as a "fit", with $31 \%$ and $43 \%$, respectively, choosing "possible". Looking at the overall tendency, and not comparing the results between the two countries, it is clear that a large proportion find that this type of work is "inappropriate" for themselves, which differs from the positive evaluation of this type of work in theoretical research and studies (Christensen, 2019; Crosbie \& Moore, 2004; Davidson, 2018; Felstead, Jewson, Phizacklea, \& Walters, 2002; James, 2018). Why is that the case? This can be explained by the need for socialization and un-readiness of respondents to work completely independently (which is more characteristic of younger people, for whom this is one of the first places of work), and, especially for the younger respondents, with the fact that they do not have the appropriate conditions for working at home, or might not have their own property from which to work, which is noted as a significant modern day problem by Heath (2016), with Latvia and Romania, as "transition economy countries" being especially affected. 
The respondents' opinion on Flex and CoW is significantly more positive than on HOT - only $10 \%$ to $20 \%$ have noted them as being "inappropriate", while $34 \%$ in Romania and $17 \%$ in Latvia have put Flex as a "fit", and more than half of the respondents in both countries stating that it is a "possible" fit. Situation is similar with CoW as well: $38 \%$ in Romania and 19\% in Latvia have marked it as a "fit", while 44\% and 67\%, respectively, put it as "possible".

From that, it can be understood that the respondents' opinion is very positive (adding up the "fit" and "possible" answers) of three of the new ways of working: HOP, Flex and CoW, and cautiously negative about HOT, the reasons behind which would be worth to look at in more detail, as various publications show a positive attitude towards it, and its popularity is expected to grow in the future (Davidson, 2018).

Question four was the most detailed, with respondents evaluating each new way of working for nine potential benefits, to determine how much (if any) positive influence the new ways of working have on these criteria.

The "My personal wellbeing in general" criteria is dominated by both HO ways of working $-64 \%$ of Romanian and $82 \%$ of Latvian respondents noted that working from home is beneficial for them. Only $2 \%$ of respondents in each country note that none of the new ways of working affect their personal wellbeing.

"Better management of personal and professional time" is the second criteria where respondents indicate the significant benefits of working HO: $70 \%$ in Romania and $68 \%$ in Latvia find that $\mathrm{HO}$ allows them to manage their time better. At the same time, $3 \%$ in Romania and 9\% in Latvia believe that the way of working has no effect on management of personal and professional time. That could be associated with the opinion that if a person does not know how to plan their time, changing their way of working will not magically improve these skills.

While the difference was not as significant, $\mathrm{HO}$ also came out on top in the "Personal learning and professional development" criteria, as noted by $38 \%$ of Romanian and $46 \%$ of Latvian respondents, while $7 \%$ and $17 \%$, respectively, believe that none of the ways of working affect their learning and development. These results are interesting, as it is clear that nearly one half of the respondents believe that it is possible to do work related learning independently (from home), while a significant part is quite pessimistic or believe that learning and sharing is only possible in the classic working space (which was not an option in the survey). This question could be analysed further by offering more choices to the respondents.

Interestingly, the benefits in criteria "My personal productivity" and "Making more efficient use of the organization I work for" are broadly similar: HO benefits are slightly dominant, as noted by, respectively 23 and $20 \%$ of Romanian, and 11 and $15 \%$ of Latvian respondents, while $4-8 \%$ believe that none of the new ways of working impact these criteria in any way.

Flex or CoW ways of working dominate in three of the nine criteria. It is most notable in the "My social relations in general", where $51 \%$ of Romanian and $46 \%$ of Latvian respondents have noted their positive influence, while $\mathrm{HO}$ have received, respectively, $28 \%$ and $36 \%$ of the responses, and $7 \%$ have noted that none of these have an effect on social relations. This result is expected, as it is not really possible to create and develop social relationships when you are working alone.

Flex and CoW have also been highly appreciated in "Learning and sharing knowledge in the organization I work in", by 55\% in Romania and 36\% in Latvia. These answers are expected, as sharing is closely related to communication and being among others. At the same, $10 \%$ and $8 \%$, respectively, have noted that none of the new ways of working affect 
learning and sharing knowledge. That can be understood as either the respondents' thinking that learning and sharing are only possible in the classic working spaces (which was not an option in the survey), or that it is done regardless of the way of working. This aspect could be researched further.

"My professional relationships" is another criteria dominated by Flex and CoW, with $47 \%$ in Romania and $29 \%$ in Latvia noting its benefits, with $29 \%$ in Romania and $10 \%$ in Latvia choosing HO. This breakdown is expected, as developing professional relationships is easier and more common, but modern technology makes effective communication possible with $\mathrm{HO}$ as well, which is why the share of HO is quite high. This criteria had most notes that none of the ways of working have a positive effect, with, respectively, $29 \%$ and $19 \%$ of the answers, which is surprising and definitely worth a more in-depth look. It is possible that here, similarly to two of the criteria discussed previously, an option about the classic way of working was needed to better understand the reasoning behind some of the answers.

Criteria "Overall performance of the organization I work for" was the only one where the answers of respondents from both countries were quite evenly spread among all of the new ways of working, which $6 \%$ had noted that none of them affect the performance of their organization. This criteria might have been too broad, and no further conclusions can be made from its results.

\section{CONCLUSION}

The small number of respondents was at once a benefit and a shortcoming of this research. On the one hand - with more respondents, the results would better represent the population as a whole. On the other hand, the results show that some adjustments need to be made to the questions if the survey is to be used for further research, so the work done until now meets the criteria of a pilot study, as was the initial intention.

A similar conclusion can be made about the respondents of both counties - the comparison between their answers would be better if the respondents themselves were more similar. However, this can also be seen as a benefit, making it possible to consider the reasons why the answers are different in some cases.

If the survey is to be used for further research, it would be necessary to adjust/supplement some of the answers. For example, instead of "none", it would be beneficial to also offer an option for "classic way of working" or something similar. It would be especially important for questions with a high proportion of "none" answers.

Question about the reasoning behind the relatively low support for HOT could be a topic for further and more detailed, and possibly even separate, research. Here, a meta-analysis of the results of other studies, as well as a respondent survey of HOT influencing factors could be made. It is known that HOT is not suitable for all types of work and that it is influenced by personal maturity, need for socialization and, possibly, age and work experience. Attention should be paid to the home environment of the respondents: do they have a place to work, are there any distractions, do they have the necessary equipment (or - who should pay for buying it), etc. From an organizational standpoint HOT, which is more effective than HOP from the facility management point of view and can help decrease office costs, is associated with monitoring those working from home, maintaining information security, and other aspects. 


\section{REFERENCES}

Blok, M., van der Meulen, F., \& Dhondt, S. (2016). A Comparison between New Ways of Working and Sociotechnical Systems. In J. D. Leede (Ed.), Advanced Series in Management, 16, 145-162.

Brunia, S., De Been, I., \& van der Voordt, T. J. M. (2016). Accommodating new ways of working: lessons from best practices and worst cases. Journal of Corporate Real Estate, 18(1), 30-47.

Capotescu, S., Malaies, L.-A., \& Soim, H.-F. (2019). Generations at Work for a better future. Proceedings in Business and Economics. Presented at the 15th International Symposium in Management: Innovation for Sustainable Management and Entrepreneurship, Timisoara, Romania.

Choudhury, P. (Raj), Larson, B. Z., \& Foroughi, C. (2019). Is It Time to Let Employees Work from Anywhere? Harvard Business Review. Retrieved from https://hbr.org/2019/08/is-it-time-to-let-employees-work-fromanywhere

Christensen, K. (Ed.). (2019). The New Era Of Home-based Work: Directions and Policies. Routledge.

Crosbie, T., \& Moore, J. (2004). Work-life Balance and Working from Home. Social Policy and Society, 3(3), 223-233.

Davidson, M. (2018). The forgotten sector. Economic Development Journal, 17(1), 11.

Felstead, A., Jewson, N., Phizacklea, A., \& Walters, S. (2002). Opportunities to work at home in the context of work-life balance. Human Resource Management Journal, 12(1), 54-76.

Heath, S. (2016). Young, free and single? Young adults and independent life arrangements. In Routledge Handbook of Youth and Young Adolthood (Second ed., pp. 199-204).

James, G. (2018). Case Closed: Work-From-Home Is the World's Smartest Management Strategy. Retrieved: https://www.inc.com/geoffrey-james/case-closed-work-from-home-is-worlds-smartest-managementstrategy.html

James, G. (2019). More Proof (If Any Were Needed) that Work-From-Home Beats Open Plan Office. Retrieved from: https:/www.inc.com/geoffrey-james/more-proof-if-any-were-needed-that-work-fromhome-beats-open-plan-office.html

Kalve, I. (2019). The modern workplace in service management: possibilities, realities, new ways of working. Proceedings in Business and Economics. Presented at the 15th International Symposium in Management: Innovation for Sustainable Management and Entrepreneurship, Timisoara, Romania.

Kelliher, C., \& Anderson, D. (2010). Doing more with less? Flexible working practices and the intensification of work. Human Relations, 63(1), 83-106.

Manca, C., Grijalvo, M., Palacios, M., \& Kaulio, M. (2018). Collaborative workplaces for innovation in service companies: barriers and enablers for supporting new ways of working. Service Business, 12(3), 525-550.

McAtamney, L., Aickin, C., Caple, D., Caponecchia, C., \& Mackey, M. (2017). Challenges and Future Research Opportunities with New Ways of Working. Retrieved from https://www.ingentaconnect.com/content/rout/2fbfgk/2017/00000001/00000001/art00019

Oldman, T. (2018). The Productivity Problem in Office Design. Retrieved from: https://facilityexecutive.com/2018/05/productivity-problem-office-design/

Schwab, K. (2019). More people are working remotely, and its transforming office design. Retrieved from: https://www.fastcompany.com/90368542/more-people-are-working-remotely-and-its-transformingoffice-design

Stegmeier, D. (2008). Innovations in Office Design: The Critical Influence Approach to Effective Work Environments. John Wiley \& Sons.

Wohlers, C., \& Hertel, G. (2017). Choosing where to work at work - towards a theoretical model of benefits and risks of activity-based flexible offices. Ergonomics, 60(4), 467-486.

\section{AUTHORS' SHORT BIOGRAPHY}

Ieva Kalve. She received the Dr.oec. degree from the University of Latvia in 2008 and is an Assistant Professor in Riga Stradins University (Latvia). Research interests: strategic and change management, sustainability, future of work, modern ways of working, office ergonomics.

E-mail address: ieva.kalve@,rsu.lv

Sebastian Capotescu. He received the Ph.D. degree from the Timisoara Polytechnic University in 2012 and is a Project Director at GreenForest S.R.L. in Timisoara (Romania). Research interests: future of work, generations at work.

E-mail address: sebastian.capotescu@greenforest.ro 